\title{
Association between matrix metalloproteinase-2 and matrix metalloproteinase-9 polymorphisms and endometriosis: A systematic review and meta-analysis
}

\author{
LINGLI XIN $^{1 *}$, QINGXIANG HOU ${ }^{1 *}$, QI XIONG ${ }^{2}$ and XIAOPING DING ${ }^{1}$ \\ ${ }^{1}$ Department of Obstetrics and Gynecology, Second Artillery General Hospital of Chinese PLA, Beijing 100088; \\ ${ }^{2}$ Department of Orthopedics, General Hospital of Chinese PLA, Beijing 100853, P.R. China
}

Received February 27, 2015; Accepted March 13, 2015

DOI: $10.3892 /$ br. 2015.447

\begin{abstract}
Matrix metalloproteinase-2 (MMP-2)-735C/T and $M M P-9-1562 \mathrm{C} / \mathrm{T}$ polymorphisms have been indicated in the predisposition to endometriosis. However, due to the small sample sizes of previous studies, the results remain inconclusive. The present meta-analysis was conducted to detect the association between the two genetic polymorphisms and the risk of endometriosis by pooling all the available data. Electronic databases, including PubMed, Embase, Web of Science and CNKI, were searched comprehensively for studies examining a link between $M M P-2$ and $M M P-9$ polymorphisms and endometriosis. The strength of the association was assessed based on the pooled odds ratio with a 95\% confidence interval, which was calculated using either the fixed- or random-effect model. Following the inclusion criteria, 6 case-control studies were included. The total number of participants was 2,486 (558 cases and 797 controls concerning the $M M P-9-1562 \mathrm{C} / \mathrm{T}$ polymorphism, and 525 cases and 606 controls concerning the $M M P-2-735 \mathrm{C} / \mathrm{T}$ polymorphism). No significant association was identified between the $M M P-2-735 \mathrm{C} / \mathrm{T}$ or $M M P-9-1562 \mathrm{C} / \mathrm{T}$ polymorphism and endometriosis. In further stratified analysis, no significant association was identified between the $M M P-9-1562 \mathrm{C} / \mathrm{T}$ polymorphism and endometriosis. The present meta-analysis revealed no association between the $M M P-2-735 \mathrm{C} / \mathrm{T}$ and MMP-9-1562C/T polymorphisms and the risk of developing endometriosis. Considering the limitations of the meta-analysis, well-designed studies with larger sample sizes are required.
\end{abstract}

Correspondence to: Dr Xiaoping Ding, Department of Obstetrics and Gynecology, Second Artillery General Hospital of Chinese PLA, 16 Xinjiekouwai Street, Beijing 100088, P.R. China

E-mail: dxp9902@tom.com

*Contributed equally

Key words: $M M P-2, M M P-9$, polymorphism, endometriosis, meta-analysis

\section{Introduction}

Endometriosis, a common estrogen-dependent gynecological disorder affecting $5-10 \%$ of women of reproductive age, is characterized by an ectopic growth of endometrial tissue at various sites outside the uterus, including the ovaries, rectouterine pouch, pelvic peritoneum and uterosacral ligaments (1-3). Endometriosis is associated with a range of symptoms, including chronic pelvic pain, dysmenorrhea and infertility, all of which can have a strong adverse effect on the physical and mental health of the patient (4). While endometriosis is assumed to be a benign disease from a histological standpoint, it bears a certain resemblance to malignant tumors due to the characteristic of infiltration (5). While the development of endometriosis has been shown to be a complex process involving interactions between genetic and environmental factors (6), the etiology and pathology of endometriosis remain poorly understood.

Matrix metalloproteinases (MMPs), a family of zinc atom-dependent endopeptidases, can be divided into three groups based on substrate preference: Collagenases (MMP-1, MMP-8 and MMP-13), gelatinases (MMP-2 and MMP-9) and stromelysins (MMP-3, MMP-10 and MMP-11) (7). MMPs play an essential role in regulating the extracellular matrix (ECM) turnover and homeostasis by degrading ECM proteins (8). Aberrant MMP expression has been indicated in tumor invasion and metastasis. A positive correlation was reported between MMP expression and the process of tumor invasion (9). Furthermore, MMPs were shown to be involved in ECM reconstruction at local endometrial implantation sites and were also shown to facilitate ectopic focus infiltration and invasion (10). Increasing evidence supports the existence of a genetic component in the development of endometriosis and suggests that disease pathogenesis is multifactorial and polygenic (11). Additionally, previous studies revealed that $M M P-2$ and $M M P-9$ genes have also been linked to endometriosis (12-14).

The MMP-9 gene is located on chromosome 20q12-13 and encodes an enzyme that participates in the degradation of collagen type IV and gelatin, which are the main components of the basement membrane; a study by Collette et al (15) showed that increased proteolysis and a concomitant increase 
in the levels of this enzyme were associated with the development of endometriosis. A study by Chung et al (16) indicated that MMP-9 played a crucial part in the implantation and invasion of ectopic endometrial tissue. The expression of MMP-9 was significantly higher in ectopic endometrial tissues compared to eutopic endometrial tissues (17). Furthermore, MMP-9 promotes angiogenesis, which is considered to be a key process in the development of endometriosis (18). Several coding single-nucleotide polymorphisms (SNPs) of MMP-9 have been identified, including MMP-9-1562C/T SNP (19). In addition, a recent study demonstrated that the transcriptional activity of the $-1562 \mathrm{~T}$ allele was higher than the $-1562 \mathrm{C}$ allele (20). Thus, the polymorphism possibly changes the protein structure of $M M P-9$, which may raise the risk of endometriosis of an individual subsequently. Collectively, the evidence from several studies suggests that polymorphisms in $M M P-9-1562 \mathrm{C} / \mathrm{T}$ may contribute to the development and progression of endometriosis.

The MMP-2 gene is located on chromosome 16q13-2 and encodes an enzyme that promotes the reconstruction of the ECM by targeting gelatin and collagens type IV, V, VII and X. In support of a role for $M M P-2$ in endometriosis, patients with endometriosis showed increased $M M P-2$ expression, while the levels of tissue inhibitors of metalloproteinase-2 (an inhibitor of $M M P-2)$ mRNA were lower (21). In agreement with this, a study by Ria et al (18) also showed an increase in the $M M P-2$ mRNA levels in endometriosis, particularly in patients with advanced disease. Additionally, the $M M P-2$ levels in the peritoneal fluid were also higher in endometriosis patients compared to the control subjects (22). Saare et al (12) demonstrated that the $M M P-2-735 \mathrm{C} / \mathrm{T}$ (4297C $>\mathrm{T})$ genotype was associated with the risk of endometriosis in Caucasian populations. However, a study by Kang et al (23) did not detect any association in Northern Chinese populations. Thus, the association between the $M M P-2$ genetic polymorphisms and endometriosis remains elusive.

Due to the small sample size in the previous studies, conclusions were drawn with a lack of statistical power. Therefore, a meta-analysis was conducted to detect the association between the two genetic polymorphisms and the risk of endometriosis by pooling all the available data, to maximize the power to detect the association and identify the potential effective markers for predicting the predisposition to endometriosis.

\section{Materials and methods}

Search strategy. A systematic literature search was carried out using multiple electronic databases, including PubMed, Embase, Web of Science and CNKI, before July 1, 2014. The following combined key terms were used: 'MMP-2', 'matrix metalloproteinase-2', 'MMP-9', 'matrix metalloproteinase-9', 'genetic polymorphisms', 'polymorphism' or 'variant' in combination with 'endometriosis'. The studies identified were confined to those involving human subjects and the language was limited to English and Chinese. When data from one research group was published in more than one study, the study with the largest sample size was selected. Two independent investigators (Q.X.H. and Q.X.) manually screened the reference lists of reviews and retrieved studies to identify additional potential studies.
Inclusion and exclusion criteria. The inclusion criteria were as follows: i) Original studies; ii) studies that evaluated the association between the $M M P-2$ or $M M P-9$ genetic polymorphisms and endometriosis; iii) case-control study; iv) studies published in English or Chinese; and v) cases were diagnosed pathologically. Studies were excluded for the following reasons: i) Review studies, meta-analysis, letters or comments; ii) duplicate studies; iii) studies without control populations; iv) studies without raw data or based on incomplete data; v) studies deviated from the Hardy-Weinberg equilibrium (HWE); and vi) studies on animal experiments. Additionally, when the data required for quantitative synthesis was unavailable, the authors were contacted to obtain the necessary information through email.

Data extraction. For the eligible studies, two investigators extracted the necessary information using a normative form. The information included: Authors' names, year of publication, country or region where the research was conducted, source of controls, number of cases and controls, mean age, genotype method, allele frequency, stage of endometriosis and diagnostic criteria. Discrepancies were solved by discussing with a third investigator (X.P.D.) until reaching a consensus when necessary.

Statistical analysis. The association between MMP-9 and $M M P-2$ genetic polymorphisms and the risk of endometriosis for each study was assessed by the calculating odds ratio (OR) and $95 \%$ confidence interval $(95 \% \mathrm{CI})$. Four models were examined: Dominant (CC+CT vs. TT), homozygote (CC vs. TT), recessive (CC vs. CT+TT) and allele (C vs. T). Inter-study heterogeneity and variations were evaluated by the $\mathrm{Q}$ statistic test and $\mathrm{I}^{2}$ test (24). The $\mathrm{I}^{2}$ test indicates that the study variability owed to heterogeneity instead of chance and the range is $0-100 \%\left(\mathrm{I}^{2}<25 \%\right.$, no heterogeneity; $\mathrm{I}^{2}=25-50 \%$; moderate; $\mathrm{I}^{2}=50-75 \%$, large; $\mathrm{I}^{2}>75 \%$, extreme) $(25) . \mathrm{P}>0.1$ or $\mathrm{I}^{2}<50 \%$ indicated that there was homogeneity among studies and the fixed-effect model was used (26). Otherwise, the random-effect model was used (27). Potential publication bias was detected using Egger's regression test (28). $\mathrm{P}<0.05$ was considered to indicate a statistically significant difference regarding publication bias. All the statistical tests were two-tailed. The HWE for each study was examined by $\chi^{2}$ test. All the analyses were performed with Comprehensive Meta-Analysis v2 software package (Biostat, Inc., Englewood, NJ, USA).

\section{Results}

Characteristics of studies included in the meta-analysis. Following the searching strategy, 70 relevant studies were initially recruited. According to the inclusion criteria, 46 full-text studies were assessed for eligibility. Subsequent to reading the full text, 15 studies were excluded and 19 that were not relevant to either $M M P-2$ or $M M P-9$ were also excluded, 5 were excluded for duplicate data and 1 was excluded for focusing on other gene polymorphisms of MMP-9 [rs17576 (R279Q) and rs2250889 (P574R)] (29). Finally, 6 studies (12,13,23,30-31) were included, of which 3 were conducted on $M M P-9$ genetic polymorphisms, 2 were conducted on $M M P-2$ genetic polymorphisms and 1 was conducted on $M M P-9$ and $M M P-2$ 
Table I. Detailed information of the MMP-9-1562C/T polymorphism studies.

\begin{tabular}{|c|c|c|c|c|c|c|c|c|c|c|c|c|}
\hline \multirow[b]{2}{*}{ Authors (year) } & \multirow[b]{2}{*}{ Country } & \multirow[b]{2}{*}{ Ethnicity } & \multirow{2}{*}{$\begin{array}{c}\text { Source of } \\
\text { control }\end{array}$} & \multirow[b]{2}{*}{ Sample } & \multirow[b]{2}{*}{ Detection } & \multicolumn{7}{|c|}{ Genotype, case/control } \\
\hline & & & & & & Total & $\mathrm{CC}$ & $\mathrm{CT}$ & TT & $\mathrm{C}$ & $\mathrm{T}$ & (Refs.) \\
\hline Kang et al (2008) & China & Asian & HB & Blood & PCR-RFLP & $143 / 160$ & $112 / 134$ & $30 / 26$ & $1 / 0$ & $254 / 294$ & $32 / 26$ & 23 \\
\hline Qu et al (2007) & China & Asian & $\mathrm{HB}$ & Blood & PCR-RFLP & $70 / 240$ & $56 / 182$ & $13 / 56$ & $1 / 2$ & $125 / 420$ & $15 / 60$ & 30 \\
\hline Han et al (2009) & Korea & Asian & HB & Blood & PCR-RFLP & $225 / 198$ & $188 / 155$ & $35 / 37$ & $2 / 6$ & $411 / 347$ & $39 / 49$ & 13 \\
\hline Saare et al (2010) & Estonia & Caucasian & $\mathrm{PB}$ & Blood & PCR-RFLP & $160 / 199$ & $100 / 146$ & $44 / 50$ & $6 / 3$ & $244 / 342$ & $66 / 56$ & 12 \\
\hline
\end{tabular}

PB, population-based; HB, hospital-based; PCR, polymerase chain reaction; RFLP, restriction fragment length polymorphism; $M M P-9$, matrix metalloproteinase-9.

Table II. Detailed information of the $M M P-2-735 \mathrm{C} / \mathrm{T}$ polymorphism studies.

\begin{tabular}{|c|c|c|c|c|c|c|c|c|c|c|c|c|c|}
\hline \multirow[b]{2}{*}{ Authors (year) } & \multirow[b]{2}{*}{ Country } & \multirow{2}{*}{ Ethnicity } & \multirow{2}{*}{$\begin{array}{c}\text { Source of } \\
\text { control }\end{array}$} & \multirow{2}{*}{ Sample } & \multirow[b]{2}{*}{ Detection } & \multicolumn{8}{|c|}{ Genotype, case/control } \\
\hline & & & & & & Total & $\mathrm{CC}$ & $\mathrm{CT}$ & $\mathrm{TT}$ & $\mathrm{CT}+\mathrm{TT}$ & $\mathrm{C}$ & $\mathrm{T}$ & (Refs.) \\
\hline Kang et al (2008) & China & Asian & HB & Blood & PCR-RFLP & $298 / 324$ & $177 / 197$ & $105 / 111$ & $16 / 16$ & $121 / 127$ & $459 / 505$ & $137 / 143$ & 23 \\
\hline Zhou et al (2013) & China & Asian & $\mathrm{HB}$ & Blood & PCR-RFLP & $77 / 83$ & $45 / 50$ & $28 / 29$ & $4 / 4$ & $32 / 33$ & $118 / 129$ & $36 / 37$ & 31 \\
\hline Saare et al (2010) & Estonia & Caucasian & $\mathrm{PB}$ & Blood & PCR-RFLP & $150 / 199$ & $124 / 142$ & & & $26 / 57$ & & & 12 \\
\hline
\end{tabular}

$\mathrm{PB}$, population-based; HB, hospital-based; $\mathrm{PCR}$, polymerase chain reaction; RFLP, restriction fragment length polymorphism; $M M P-2$, matrix metalloproteinase-2.

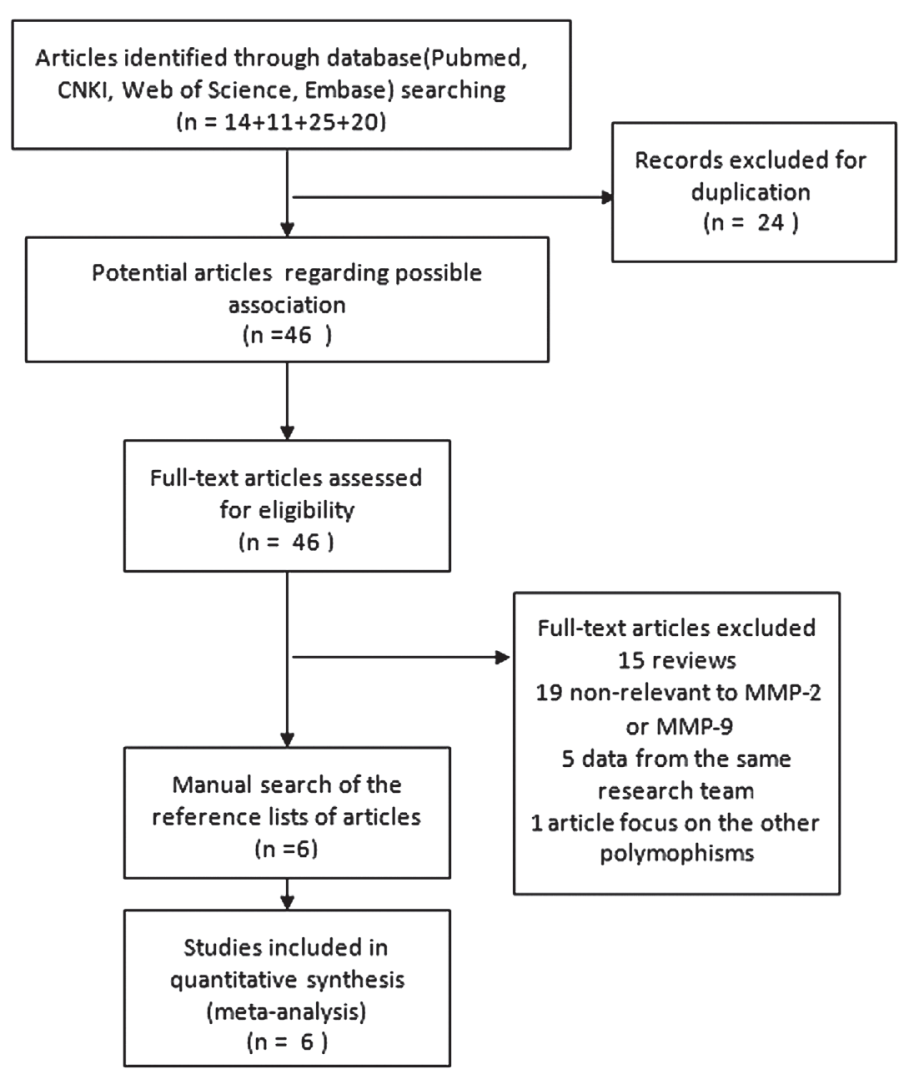

Figure 1. Flow chart showing the study selection procedure. MMP, matrix metalloproteinase.

genetic polymorphisms. A total of 558 cases and 797 controls studying the MMP-9-1562C/T polymorphism and 525 cases and 606 controls studying the $M M P-2-735 \mathrm{C} / \mathrm{T}$ polymorphism were included. Of the 6 studies, 5 were conducted in Asian populations (4 in China and 1 in Korea) and 1 was conducted in Caucasian populations (Estonia). The flow chart detailing the study selection is shown in Fig. 1. The basic characteristics of the eligible studies are shown in Tables I and II. 
A

\begin{tabular}{lllrrrr}
\hline Study name & \multicolumn{5}{c}{ Statistics for each study } \\
\cline { 3 - 7 } & $\begin{array}{c}\text { Odds } \\
\text { ratio }\end{array}$ & $\begin{array}{c}\text { Lower } \\
\text { limit }\end{array}$ & $\begin{array}{r}\text { Upper } \\
\text { limit }\end{array}$ & Z-Value & p-Valu \\
Kang 2006 & 0.296 & 0.012 & 7.323 & -0.744 & 0.4 \\
Qu 2007 & 0.580 & 0.052 & 6.491 & -0.442 & 0.658 \\
Han 2009 & 3.484 & 0.695 & 17.465 & 1.518 & 0.129 \\
Saare 2010 & 0.367 & 0.090 & 1.493 & -1.400 & 0.1 \\
& 0.813 & 0.322 & 2.056 & -0.437 & 0.6
\end{tabular}

\section{Odds ratio and $95 \% \mathrm{Cl}$}

0.457
0.658
0.129
0.162
0.662

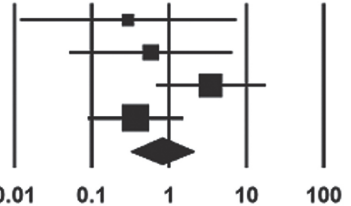

Favours case Favours control

dominant model

\begin{tabular}{llllrrr} 
Study name & \multicolumn{5}{c}{ Statistics for each study } \\
\cline { 1 - 6 } & $\begin{array}{c}\text { Odds } \\
\text { ratio }\end{array}$ & $\begin{array}{c}\text { Lower } \\
\text { limit }\end{array}$ & $\begin{array}{c}\text { Upper } \\
\text { limit }\end{array}$ & Z-Value & p-Value \\
Kang 2006 & 0.279 & 0.011 & 6.911 & -0.780 & 0.436 \\
Qu 2007 & 0.615 & 0.055 & 6.914 & -0.393 & 0.694 \\
Han 2009 & 3.639 & 0.724 & 18.283 & 1.568 & 0.117 \\
Saare 2010 & 0.342 & 0.084 & 1.401 & -1.491 & 0.136 \\
& 0.805 & 0.317 & 2.040 & -0.458 & 0.647
\end{tabular}

homozygote comparison

Study name

\begin{tabular}{lll} 
Odds & \multicolumn{3}{c}{ Statistics for each study } \\
ratio & $\begin{array}{c}\text { Lower } \\
\text { limit limit Z-Value } p \text {-Value }\end{array}$
\end{tabular}

$\begin{array}{llllll}\text { Kang } 2006 & 0.701 & 0.393 & 1.250 & -1.204 & 0.229\end{array}$

$\begin{array}{llllll}\text { Qu } 2007 & 1.275 & 0.661 & 2.456 & 0.725 & 0.468\end{array}$

Han $2009 \quad 1.410 \quad 0.865 \quad 2.297 \quad 1.378 \quad 0.168$

$\begin{array}{lllll}\text { Saare } 2010 & 0.726 & 0.457 & 1.153 & -1.356\end{array}$

$\begin{array}{llll}0.962 & 0.737 & 1.254 & -0.288\end{array}$

0.175

0.773

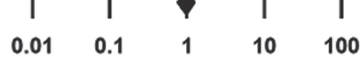

Favours case Favours control

D

recessive model

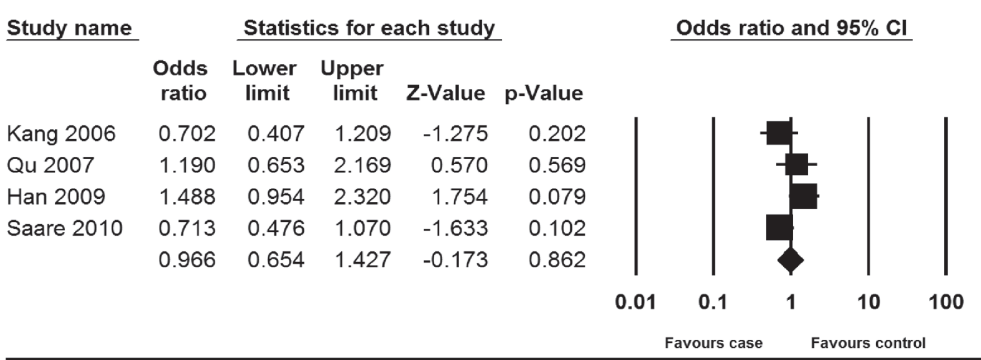

allele model

Figure 2. Forest plot of the meta-analysis of the MMP-9-1562C/T polymorphism. (A) Dominant; (B) homozygote; (C) recessive; and (D) allele models. The size of the square represent the sample size of the study. $M M P-9$, matrix metalloproteinase-9; CI, confidence interval.

Meta-analyses for MMP-9-1562C/T polymorphisms and the risk of endometriosis. The meta-analysis revealed no significant association between the MMP-9-1562C/T polymorphism and the risk of endometriosis (dominant model: OR, 0.813; 95\% CI, 0.322-2.056; $\mathrm{P}=0.662$; homozygote model: $\mathrm{OR}, 0.805$; 95\% CI, 0.317-2.040; $\mathrm{P}=0.647$; recessive model: OR, 0.962; 95\% CI, 0.737-1.254; $\mathrm{P}=0.773$; and allele model: OR, 0.966; 95\% CI, 0.654-1.427; P=0.862) (Fig. 2).

In the further ethnicity-based analysis, no association was detected between the MMP-9-1562C/T polymorphism and endometriosis risk in Asian populations (dominant model: OR, 1.509; 95\% CI, 0.438-5.199; P=0.515; homozygote model: OR, 1.577; 95\% CI, 0.451-5.376; $\mathrm{P}=0.483$; recessive model: OR, 1.104; 95\% CI, 0.798-1.527; $\mathrm{P}=0.549$; and allele model: OR, 1.123; 95\% CI, 0.833-1.514; P=0.446) (Fig. 3).
Meta-analyses for the MMP-2-735C/T polymorphism and risk of endometriosis. Considering the limited data available on the $M M P-2-735 \mathrm{C} / \mathrm{T}$ polymorphism, only the homozygote model was analyzed. Similar to the $M M P-9$ polymorphism results, the analysis did not reveal a significant association between the $M M P-2-735 \mathrm{C} / \mathrm{T}$ polymorphism and the risk of endometriosis (homozygote model: OR, 1.173; 95\% CI, 0.741-1.858; $\mathrm{P}=0.496$ ). (Fig. 4)

Heterogeneity analyses. There was no significant heterogeneity among the studies that examined the association between the $M M P-9-1562 \mathrm{C} / \mathrm{T}$ polymorphism and the risk of endometriosis, in any of the genetic models (dominant: $\mathrm{I}^{2}=37.762 \%, \mathrm{P}=0.185$; homozygote: $\mathrm{I}^{2}=42.683 \%, \mathrm{P}=0.155$; recessive: $\mathrm{I}^{2}=46.72 \%$, $\mathrm{P}=0.131$; and allele: $\mathrm{I}^{2}=60.36 \%, \mathrm{P}=0.056$ ). Subsequently, the 
A

\begin{tabular}{llllrrr}
\hline \multicolumn{1}{c}{ Study name } & \multicolumn{5}{c}{ Statistics for each study } \\
\cline { 4 - 7 } & $\begin{array}{c}\text { Odds } \\
\text { ratio }\end{array}$ & $\begin{array}{c}\text { Lower } \\
\text { limit }\end{array}$ & $\begin{array}{c}\text { Upper } \\
\text { limit }\end{array}$ & Z-Value & p-Value \\
Kang 2006 & 0.296 & 0.012 & 7.323 & -0.744 & 0.457 \\
Qu 2007 & 0.580 & 0.052 & 6.491 & -0.442 & 0.658 \\
Han 2009 & 3.484 & 0.695 & 17.465 & 1.518 & 0.129 \\
& 1.509 & 0.438 & 5.199 & 0.652 & 0.515
\end{tabular}

Odds ratio and $95 \% \mathrm{Cl}$

,

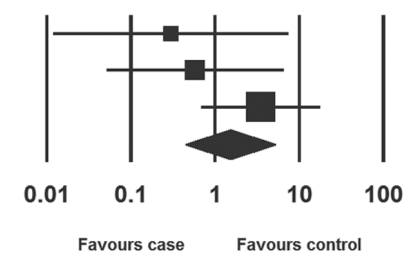

dominant model

B

\begin{tabular}{llllrrr}
\hline \multirow{2}{*}{ Study name } & \multicolumn{5}{c}{ Statistics for each study } \\
\cline { 3 - 6 } & & $\begin{array}{c}\text { Odds } \\
\text { ratio }\end{array}$ & $\begin{array}{c}\text { Lower } \\
\text { limit }\end{array}$ & $\begin{array}{c}\text { Upper } \\
\text { limit }\end{array}$ & Z-Value & p-Value \\
Kang 2006 & 0.279 & 0.011 & 6.911 & -0.780 & 0.436 \\
Qu 2007 & 0.615 & 0.055 & 6.914 & -0.393 & 0.694 \\
Han 2009 & 3.639 & 0.724 & 18.283 & 1.568 & 0.117 \\
& 1.557 & 0.451 & 5.376 & 0.701 & 0.483
\end{tabular}

Odds ratio and $95 \% \mathrm{Cl}$

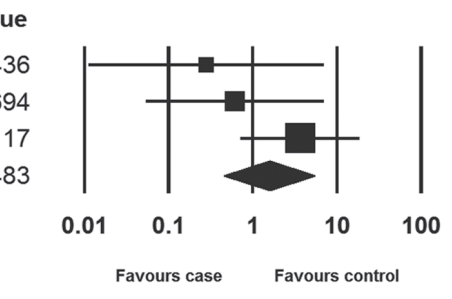

homozygote model

C

\begin{tabular}{|c|c|c|}
\hline Study name & Statistics for each study & Odds ratio and $95 \% \mathrm{Cl}$ \\
\hline
\end{tabular}

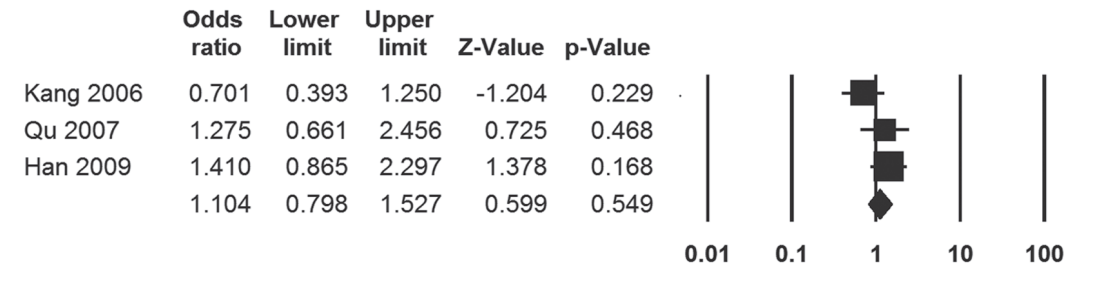

Favours case Favours control

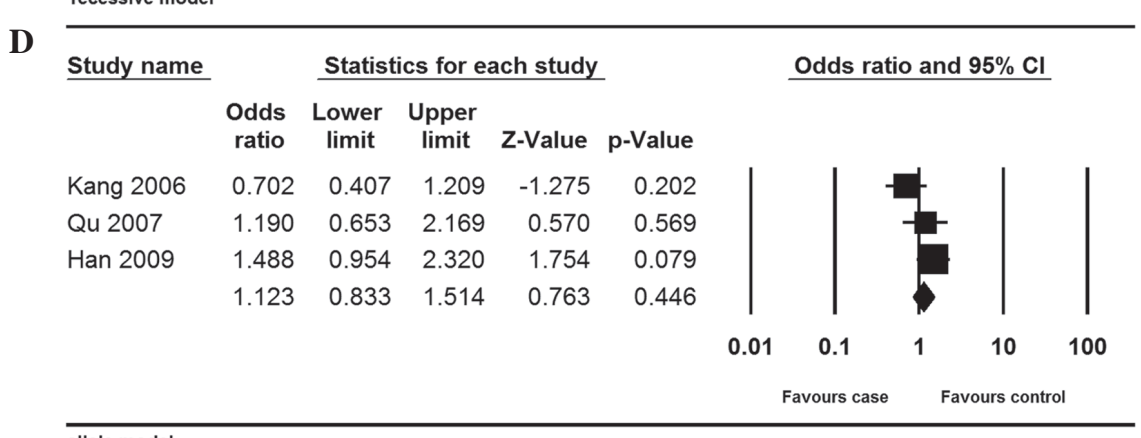

allele model

Figure 3. Forest plot of the meta-analysis of the MMP-9-1562C/T polymorphism in the Asian population. (A) Dominant; (B) homozygote; (C) recessive; and (D) allele models. The size of the square represent the sample size of the study. $M M P-9$, matrix metalloproteinase-9; CI, confidence interval.

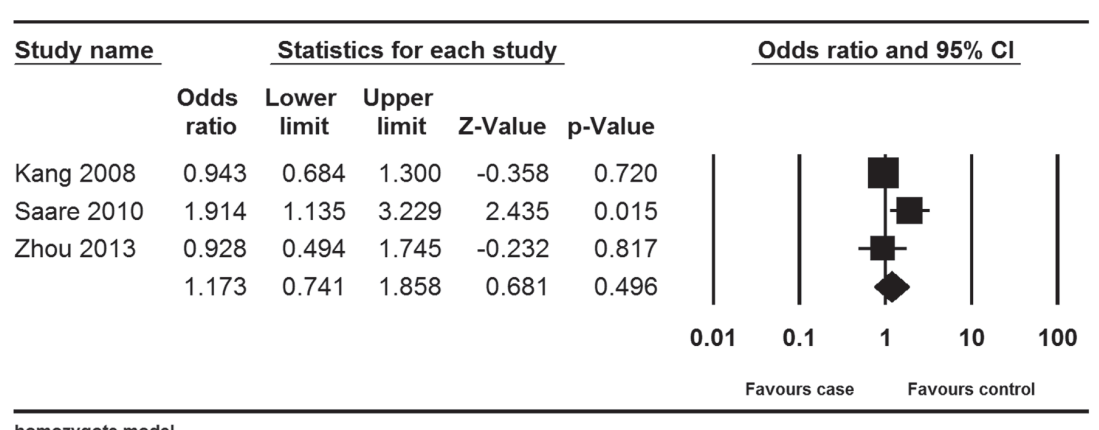

homozygote model

Figure 4. Forest plot of the meta-analysis of the $M M P-2-735 \mathrm{C} / \mathrm{T}$ polymorphism; homozygote model. The size of the square represent the sample size of the study. $M M P-2$, matrix metalloproteinase-2; CI, confidence interval. 
heterogeneity for all the genetic models was examined in Asian populations. The heterogeneity was also non-significant in all four models (dominant: $\mathrm{I}^{2}=23.896 \%, \mathrm{P}=0.269$; homozygote: $\mathrm{I}^{2}=26.75 \%, \mathrm{P}=0.255$; recessive: $\mathrm{I}^{2}=43.097 \%, \mathrm{P}=0.172$; and allele: $\left.\mathrm{I}^{2}=55.005 \%, \mathrm{P}=0.108\right)$. In addition, there was no significant heterogeneity among studies that examined the association between the $M M P-2-735 \mathrm{C} / \mathrm{T}$ polymorphism and the risk of endometriosis in the homozygote model $\left(\mathrm{I}^{2}=63.471 \%, \mathrm{P}=0.065\right)$.

Publication bias analyses. Egger's test was used to assess the potential publication bias in the recruited studies. For the MMP-9-1562C/T polymorphism, the present study showed that there was no statistical significance of publication bias (dominant model: $\mathrm{P}=0.821$; homozygote model: $\mathrm{P}=0.836$; recessive model: $\mathrm{P}=0.821$; and allele model: $\mathrm{P}=0.862$ ). When analyzing the studies conducted in Asian populations, there was also no statistical evidence of publication bias (dominant model: $\mathrm{P}=0.142$; homozygote model: $\mathrm{P}=0.121$; recessive model: $\mathrm{P}=0.785$; and allele model: $\mathrm{P}=0.618)$. Similar results were obtained for the $M M P-2-735 \mathrm{C} / \mathrm{T}$ polymorphism, also ruling out publication bias (homozygote model: $\mathrm{P}=0.703$ ).

\section{Discussion}

Endometriosis is one of the most common diseases affecting women of reproductive age. Thus far, the pathogenesis of this disease remains poorly understood. Endometriosis is considered a benign disease that nonetheless has the property of tissue invasion, which is a typical characteristic of malignant tumors. The tissue invasion process involves three important steps: Cell attachment to the ECM, proteolysis in the ECM and migration of cells (32). Increasing evidences suggests that the members of the MMP family are involved in the formation of the proteolytic defect in the basement membrane, a process that is vital for invasion of ectopic endometrial cells (8). However, owing to the small sample size, no clear conclusions can be drawn regarding the roles of $M M P-2$ and $M M P-9$ genetic polymorphisms in the pathogenesis of endometriosis. To elucidate the association, the present meta-analysis was performed.

In the meta-analysis, no significant association was identified between the MMP-9-1562C/T polymorphism and endometriosis. Stratified analysis suggested that there was no association in Asian populations either. This finding is consistent with that from a previous study by Kang et al (23). This result may be explained by the fact that endometriosis is a complex process arising from interactions between environmental and genetic factors, and involves certain biological pathways and various genetic polymorphisms. Therefore, the risk factor of endometriosis may not be able to act independently, but interact with each other closely to produce the disease. Furthermore, different linkage disequilibrium patterns exist in associated genes and the effects of polymorphisms may be obscured by certain unidentified genes (33). Therefore, these conclusions should be taken with caution.

The present study could also not detect an association between the $M M P-2-735 \mathrm{C} / \mathrm{T}$ polymorphism and endometriosis risk. A previous study suggested that the presence of the $M M P-2-735 \mathrm{C} / \mathrm{T}$ allele may increase the risk of endometriosis, as increased $M M P-2$ transcriptional and enzymatic activities contribute to the invasion and implantation of endometrial tissues at ectopic sites (12). The findings of the study are thus inconsistent with those of previous studies. Other $M M P-2$ genetic polymorphisms should also be considered as they may be involved in disease pathogenesis, while the present study only focused on the $M M P-2-735 \mathrm{C} / \mathrm{T}$ polymorphism. Finally, due to the limited available data, the association was only analyzed under the homozygote model. Thus, more data is required to elucidate the association between the $M M P-2-735 \mathrm{C} / \mathrm{T}$ polymorphism and endometriosis.

In interpreting the results of the meta-analysis, certain other limitations require to be acknowledged. First, although no publication bias was determined using the Egger's regression test, selection bias may still exist, since the languages were limited to English and Chinese, and studies reporting negative results may have been more difficult to publish than those with positive results. Second, the source of controls was not defined uniformly, as they were composed of a healthy population or hospital-based population. Third, it is more reasonable to perform stratified analyses, as a variety of factors, including age, geographic distribution and stage of endometriosis, may contribute certain confounding bias; however, insufficient data were available to conduct stratified analyses. Finally, certain potential elements may influence the analysis.

In conclusion, the present meta-analysis indicated that the $M M P-9-1562 \mathrm{C} / \mathrm{T}$ and $M M P-2-735 \mathrm{C} / \mathrm{T}$ polymorphisms may not be associated with the risk of endometriosis. Considering the limitations of the meta-analysis, well-designed studies with large-sample sizes are required prior to drawing any firm conclusions.

\section{References}

1. Giudice LC and Kao LC: Endometriosis. Lancet 364: 1789-1799, 2004.

2. D'Hooghe T and Forman A: European accreditation of endometriosis centers of expertise? Gynecol Obstet Invest 76: 1-3, 2013.

3. Jenkins S, Olive DL and Haney AF: Endometriosis: Pathogenetic implications of the anatomic distribution. Obstet Gynecol 67: 335-338, 1986.

4. Bhanoori M, Arvind Babu K, Pavankumar Reddy NG, Lakshmi Rao K, Zondervan K, Deenadayal M, Kennedy S and Shivaji S: The vascular endothelial growth factor (VEGF) $+405 \mathrm{G}>\mathrm{C}$ 5'-untranslated region polymorphism and increased risk of endometriosis in South Indian women: A case control study. Hum Reprod 20: 1844-1849, 2005.

5. Varma R, Rollason T, Gupta JK and Maher ER: Endometriosis and the neoplastic process. Reproduction 127: 293-304, 2004

6. Signorile PG and Baldi A: Endometriosis: New concepts in the pathogenesis. Int J Biochem Cell Biol 42: 778-780, 2010.

7. Trojanek J: Matrix metalloproteinases and their tissue inhibitors. Postepy Biochem 58: 353-362, 2012 (In Polish).

8. Ray JM and Stetler-Stevenson WG: The role of matrix metalloproteases and their inhibitors in tumour invasion, metastasis and angiogenesis. Eur Respir J 7: 2062-2072, 1994.

9. Stetler-Stevenson WG, Liotta LA, Kleiner DE Jr: Extracellular matrix 6: Role of matrix metalloproteinases in tumor invasion and metastasis. FASEB J 7: 1434-1441, 1993.

10. Osteen KG, Yeaman GR and Bruner-Tran KL: Matrix metalloproteinases and endometriosis. Semin Reprod Med 21: 155-164, 2003.

11. Rahmioglu N, Nyholt DR, Morris AP, Missmer SA, Montgomery GW and Zondervan KT: Genetic variants underlying risk of endometriosis: Insights from meta-analysis of eight genome-wide association and replication datasets. Hum Reprod Update 20: 702-716, 2014.

12. Saare M, Lamp M, Kaart T, Karro H, Kadastik U, Metspalu A, Peters $M$ and Salumets A: Polymorphisms in MMP-2 and MMP-9 promoter regions are associated with endometriosis. Fertil Steril 94: 1560-1563, 2010. 
13. Han YJ, Kim HN, Yoon JK, Yi SY, Moon HS, Ahn JJ, Kim HL and Chung HW: Haplotype analysis of the matrix metalloproteinase-9 gene associated with advanced-stage endometriosis. Fertil Steril 91: 2324-2330, 2009.

14. Rahmioglu N, Missmer SA, Montgomery GW and Zondervan KT: Insights into Assessing the Genetics of Endometriosis. Curr Obstet Gynecol Rep 1: 124-137, 2012.

15. Collette T, Bellehumeur C, Kats R, Maheux R, Mailloux J, Villeneuve $\mathrm{M}$ and Akoum A: Evidence for an increased release of proteolytic activity by the eutopic endometrial tissue in women with endometriosis and for involvement of matrix metalloproteinase-9. Hum Reprod 19: 1257-1264, 2004.

16. Chung HW, Wen Y, Chun SH, Nezhat C, Woo BH and Lake Polan M: Matrix metalloproteinase-9 and tissue inhibitor of metalloproteinase-3 mRNA expression in ectopic and eutopic endometrium in women with endometriosis: A rationale for endometriotic invasiveness. Fertil Steril 75: 152-159, 2001.

17. Yunying Y, Xinhua G, Jinhua Q: The expression of matrix metalloproteinase 9 and tissue inhibitor of metalloproteinase 3 in endometriosis. Xian Dai Fu Chan Ke Jin Zhan 12: 25-27, 2003 (In Chinese).

18. Ria R, Loverro G, Vacca A, Ribatti D, Cormio G, Roccaro AM and Selvaggi L: Angiogenesis extent and expression of matrix metalloproteinase-2 and -9 agree with progression of ovarian endometriomas. Eur J Clin Invest 32: 199-206, 2002.

19. Zhang B, Henney A, Eriksson P, Hamsten A, Watkins H and Ye S: Genetic variation at the matrix metalloproteinase-9 locus on chromosome 20q12.2-13.1. Hum Genet 105: 418-423, 1999.

20. Zhang B, Ye S, Herrmann SM, Eriksson P, de Maat M, Evans A Arveiler D, Luc G, Cambien F, Hamsten A, et al: Functional polymorphism in the regulatory region of gelatinase B gene in relation to severity of coronary atherosclerosis. Circulation 99 1788-1794, 1999

21. Chung HW, Lee JY, Moon HS, Hur SE, Park MH, Wen Y and Polan ML: Matrix metalloproteinase-2, membranous type 1 matrix metalloproteinase and tissue inhibitor of metalloproteinase-2 expression in ectopic and eutopic endometrium. Fertil Steril 78: 787-795, 2002.
22. Huang HF, Hong LH, Tan Y and Sheng JZ: Matrix metalloproteinase 2 is associated with changes in steroid hormones in the sera and peritoneal fluid of patients with endometriosis. Fertil Steril 81: 1235-1239, 2004.

23. Kang S, Zhao XW, Wang N, Chen SC, Zhou RM and Li Y. Association of polymorphisms of the MMP-2 and TIMP-2 genes with the risk of endometriosis in North Chinese women. Fertil Steril 90: 2023-2029, 2008

24. Lau J, Ioannidis JP and Schmid CH: Quantitative synthesis in systematic reviews. Ann Intern Med 127: 820-826, 1997.

25. Higgins JP and Thompson SG: Quantifying heterogeneity in a meta-analysis. Stat Med 21: 1539-1558, 2002.

26. Mantel N and Haenszel W: Statistical aspects of the analysis of data from retrospective studies of disease. J Natl Cancer Inst 22: 719-748, 1959.

27. DerSimonian R and Laird N: Meta-analysis in clinical trials Control Clin Trials 7: 177-188, 1986.

28. Egger M, Davey Smith G, Schneider M and Minder C: Bias in meta-analysis detected by a simple, graphical test. BMJ 315: 629-634, 1997.

29. Yarmolinskaya M, Molotkov A, Bezhenar V, Shved NY, Ivaschenko T and Baranov V: Matrix metalloproteinases's association of polymorphisms of MMP3 and MMP9 with development of genital endometriosis. Russ J Genet 50: 205-210, 2014

30. Qu Y, Li Y and Yang M: Association of polymorphisms of the MMP 9 with the risk of endometriosis and adenomyosis. Zhong Guo Mei Tan Gong Ye Yi Xue Za Zhi 10: 1079-1080, 2007 (In Chinese).

31. Zhou M, Guo R, Zeng X, Wang C, Luo Y and Huang X: Correlation between promoter polymorphism of MMP 2 and susceptibility of endometriosis. Hai Nan Yi Xue Yuan Xue Bao 19: 15-17, 2013 (In Chinese).

32. Fidler IJ and Radinsky R: Genetic control of cancer metastasis. J Natl Cancer Inst 82: 166-168, 1990.

33. Wang J, Guo X, Yu S, Song J, Zhang J, Cao Z, Wang J, Liu M and Dong W: Association between CD14 gene polymorphisms and cancer risk: A meta-analysis. PLoS One 9: e100122, 2014. 